Article

\title{
Forecast for Artificial Muscle Tremor Behavior Based on Dynamic Additional Grey Catastrophe Prediction
}

\author{
Yu Fu ${ }^{1}$ (D) , Jianjun Yao ${ }^{1}$, Honghao Zhao ${ }^{2, *}{ }^{(D)}$, Gang Zhao ${ }^{1}$ and Zhenshuai Wan ${ }^{1}$ \\ 1 Institute of Intelligent Manufacturing and Robotics, College of Mechanical and Electrical Engineering, \\ Harbin Engineering University, Harbin 150001, China; 18345032884@163.com (Y.F.); travisyao@126.com (J.Y.); \\ zhaogang@hrbeu.edu.cn (G.Z.); 18242311944@163.com (Z.W.) \\ 2 Department of Decision Science, School of Business, Macau University of Science and Technology, \\ Macau 999078, China \\ * Correspondence: hhzhao@must.edu.mo; Tel.: +86-185-7566-5064
}

Received: 24 January 2018; Accepted: 16 February 2018; Published: 24 February 2018

\begin{abstract}
Recently, bio-inspired artificial muscles based on ionic polymers have shown a bright perspective in engineering and medical research, but the inherent tremor behavior can cause instability of output response. In this paper, dynamic additional grey catastrophe prediction (DAGCP) is proposed to forecast the occurrence time of tremor behavior, providing adequate preparation time for the suppression of the chitosan-based artificial muscles. DAGCP constructs various dimensions of time subsequence models under different starting points based on the threshold of tremor occurrence times and peak-to-peak values in unit time. Next, the appropriate subsequence is selected according to grey correlation degree and prediction accuracy, then it is updated with the newly generated values to achieve a real-time forecast of forthcoming tremor time. Compared with conventional grey catastrophe prediction (GCP), the proposed method has the following advantages: (1) the degradation of prediction accuracy caused by the immobilization of original parameters is prevented; (2) the dynamic input, real-time update and gradual forecast of time sequence are incorporated into the model. The experiment results show that the novel DAGCP can predict forthcoming tremor time earlier and more accurately than the conventional GCP. The generation mechanism of tremor behavior is illustrated as well.
\end{abstract}

Keywords: artificial muscle; dynamic additional grey catastrophe prediction; tremor behavior; occurrence time

\section{Introduction}

Artificial muscle, as one of the most promising smart materials, has attracted great attention for its potential applications in intelligent robots, artificial organs and biomedical devices in recent decades [1-5]. Due to the impressive characteristics of light weight, high flexibility, super agility and long durability [6-10], plentiful research results have been reported regarding the properties of artificial muscle. Li et al. [11] proposed a novel cantilever beam artificial muscle using single-walled carbon nanotubes, which showed superfast response and ultrahigh mechanical output power density. Lu et al. [12] put forward an artificial muscle based on multi-walled carbon nanotubes, ionic liquids and biopolymer chitosan, performing an excellent bio-compatibility. Jager et al. [13] studied the electrically-controllable characteristics of conjugated polymers artificial muscles and applied them to the drug injection therapy. Then, Escudero et al. [14] designed a magnetically sensitive actuator with a ball screw and rare-earth magnet coreless, which was compact enough to be used in practical artificial prosthesis, and the limitations of high-price and lower-power in conventional electrochemical polymer actuations were overcome. Recently, Kim and Kwon [15] developed a hybrid muscle powered 
by skeletal muscle cells based on multi-walled carbon nanotubes. It provides potential for substantial innovation in the next generation of cell-based biohybrid microsystems.

Although the above research results look appealing, with the bionics research moving forward, researchers start to realize the rhythmic and involuntary contraction characterized by oscillations of the muscle which implies the instability of the muscle's output response. Such a drawback definitely limits the applications of artificial muscle in clinical medicine and industrial production. Obviously, capturing the tendency of tremor behavior can provide adequate time for the suppression of the tremor, which is essential to the improvement of the artificial muscle's output performance. Normally, the tremor behavior of artificial muscle can be characterized by the tremor occurrence times and maximum peak-to-peak values which can be predicted by applying grey systems theory.

The grey systems theory, established by Deng [16] in 1982, focuses on uncertainty systems with small samples, which has been widely used in education, industry, agriculture, medicine and other fields [17-23]. Grey prediction, an important part of grey systems theory, can provide scientific and reasonable forecasts on the future states of grey systems. For the requirement of solving practical problems, many improvements have been proposed by researchers to obtain accurate prediction results. According to their features and functions, grey predictions can be classified into grey sequence prediction, grey topological prediction, grey catastrophe prediction and seasonal system prediction, etc. [24-27]. Among them, grey catastrophe prediction (GCP) is essentially the prediction for the time distribution of abnormal values and it can forecast the forthcoming catastrophe moments to help relevant persons to prepare for the worst conditions in advance [28-31].

In this paper, based on the generation mechanism of tremor behavior, a novel DAGCP method is proposed to forecast the tremor occurrence time of artificial muscles. Due to the importance of occurrence times and maximum peak-to-peak values in unit time for muscle tremor behavior, the time subsequence models under different starting points and dimensions are constructed. Then, the appropriate dimension is selected based on grey correlation degree and model precision, and updated with the newly generated values to forecast the forthcoming tremor time. The prediction results are compared with actual time series values for evaluating relative error and accuracy. Furthermore, in order to prove the effectiveness and reliability of the proposed method, repeated experiments are carried out for GCP and DAGCP based on 10 groups of chitosan-based artificial muscles with different process parameters. Finally, some significant conclusions are discussed.

\section{Materials and Methods}

\subsection{Materials and Fabrication of Artificial Muscle}

Chitosan powder (deacetylation degree 85\%) was purchased from Jingchun biochemical technology limited company (Shanghai, China). Dilute acid (HA) (Hengxing chemical reagents limited company, Tianjin, China), multi-walled carbon nanotubes aqueous dispersion (Boyu material technology limited company, Beijing, China), glycerin (Dongli chemical reagent factory of Tianjin University, Tianjin, China), etc. were applied as the ingredients.

The basic processes of muscle include the preparation of actuation film, the synthesis of electrode film and hot embossing course as shown in Figure 1. Chitosan powder was added to $2 \%$ dilute acid solution, and the mixture was stirred for $30 \mathrm{~min}$ at $60{ }^{\circ} \mathrm{C}$ water bath, then multi-walled carbon nanotubes (MCNTs) aqueous dispersion was gradually added into the above mixture for another $15 \mathrm{~min}$. After ultrasonic oscillation, a homogeneous electrode solution was obtained and poured into a square mold $\left(50 \mathrm{~mm} \times 50 \mathrm{~mm} \times 4 \mathrm{~mm}\right.$ ). The electrode film is formed in an oven at $80^{\circ} \mathrm{C}$ for $6 \mathrm{~h}$. Meanwhile, the actuation solution was prepared through appending chitosan powder and glycerin into the HA solution, and the mixture was stirred for $15 \mathrm{~min}$ at $60^{\circ} \mathrm{C}$. After ultrasonic oscillation, the solution was poured into the mold and placed in the oven at $80^{\circ} \mathrm{C}$ for about $4 \mathrm{~h}$. Finally, the electrode film and actuation film were fabricated by the hot-pressing method for $20 \mathrm{~min}$ at $30^{\circ} \mathrm{C}$. 


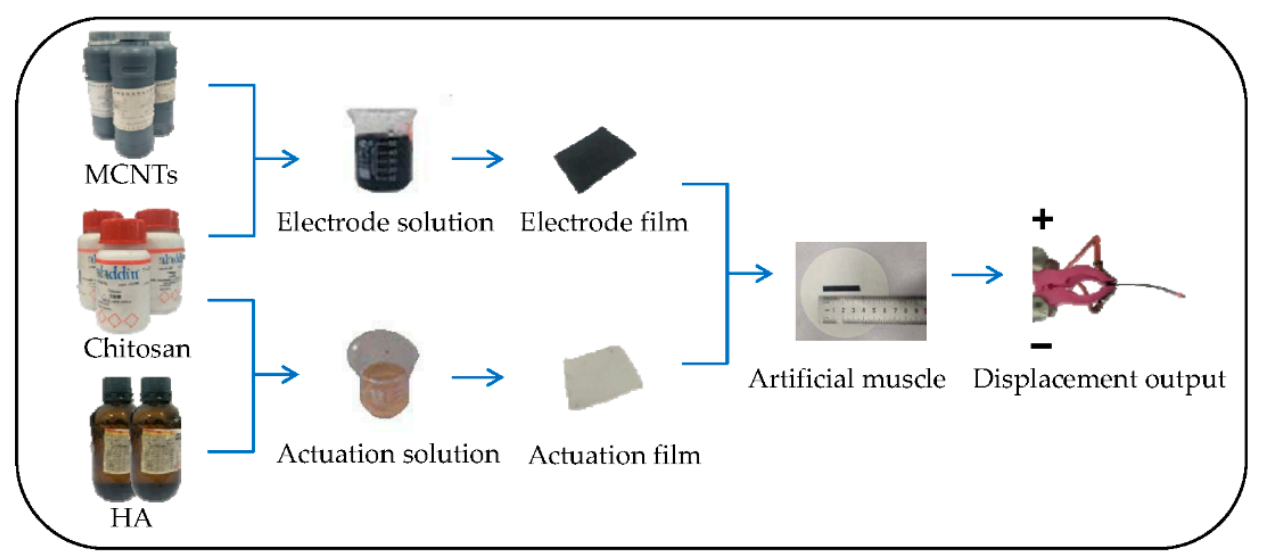

Figure 1. Basic processes of chitosan-MCNTs muscle. MCNTs: multi-walled carbon nanotubes.

\subsection{Measurement Methods and Bending Mechanism}

The experiment system and deflection displacement model were established for testing the deflection displacements of the prepared artificial muscle samples, as shown in Figures 2 and 3, respectively. Under the effect of direct current (DC) voltage, the muscle sample achieved cathode deflection by overcoming the inherent bending stress, and real-time measurements $d$ were collected from a laser displacement sensor device. After enough data was collected, a curve of time dependent displacement was drawn.

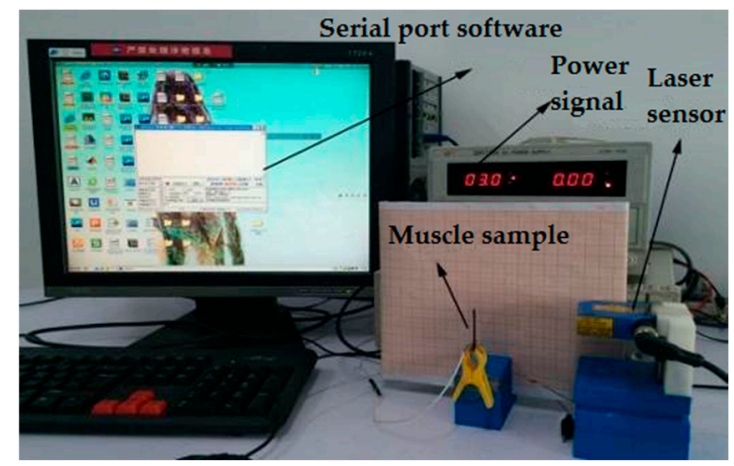

Figure 2. Muscle testing system on deflection displacement.
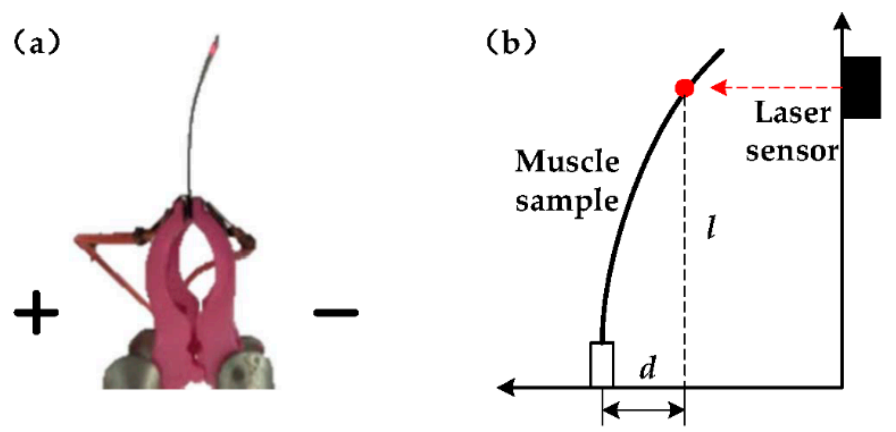

Figure 3. Deflection displacement model of artificial muscle: (a) Experimental testing; (b) Deflection displacement model.

As a polymer material with good chemical stability, its side chains distribute a large number of amino $\left(-\mathrm{NH}_{2}\right)$ after taking off the acetyl from the $40 \%$ sodium hydroxide solution. In general, 
dilute acids (HA) with concentrations of $2 \%$ are used as solvents. Figure 4 presents the schematic diagram of artificial muscle motion mechanism. During hydrolysis, several free amino groups $\left(-\mathrm{NH}_{2}\right)$ from the molecular side chains are combined with hydrogen ions $\left(\mathrm{H}^{+}\right)$in solvent to form charged polyelectrolyte $\left(-\mathrm{NH}_{3}{ }^{+}\right)$; free anions $\left(-\mathrm{A}^{-}\right)$are in a scattered state. Available dilute anions $\left(-\mathrm{A}^{-}\right)$include hydrochloric acid root $\left(\mathrm{Cl}^{-}\right)$and acetic acid root $\left(\mathrm{Ac}^{-}\right)$. When applying a lower DC voltage (under $3 \mathrm{~V}$ ) to the muscle, anions $\left(-\mathrm{A}^{-}\right)$move towards the positive electrode under Van Der Waals force; however, the polyelectrolytes $\left(-\mathrm{NH}_{3}{ }^{+}\right)$remain stationary owing to the restriction of chitosan molecular chains. The positive electrode expands and deflects to the cathode under the aggregations of anions $\left(-\mathrm{A}^{-}\right)$, resulting in the displacement output of artificial muscle.

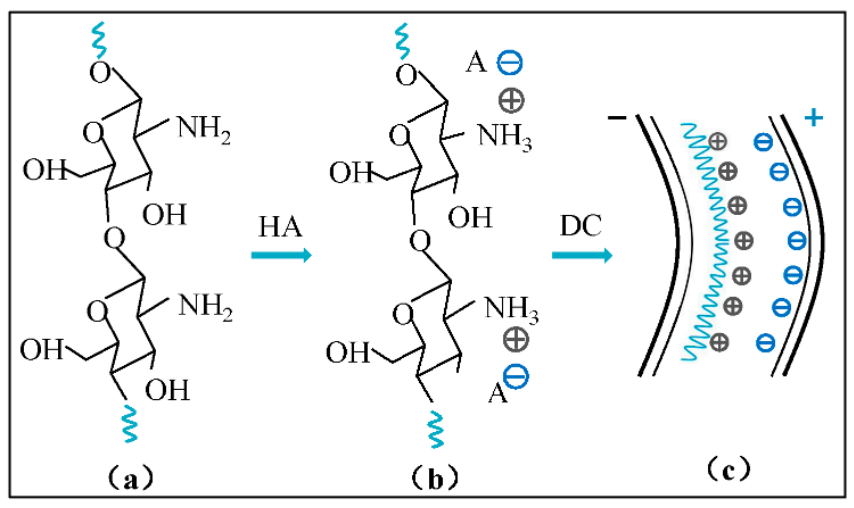

Figure 4. Schematic diagram of artificial muscle motion mechanism: (a) Chitosan structure after deacetylation; (b) Chitosan structure after dissolving in dilute acid; (c) The muscle deflection after electricity.

\subsection{Tremor Behavior Analysis}

In this work, the tremor behavior of muscles refers to the rhythmic and involuntary contraction characterized by oscillations of the muscle. It is an urgent issue for improving the stability of output response.

The surface microscopic structures of actuation film samples are illustrated in Figure 5. It can be seen that the overall structure of the actuation film is complete and compact without cracks, which can ensure expected muscle deflection. However, there are many obvious wrinkled areas and spatial agglomerations after it was magnified 5000 times. It will affect the normal movement of ions and cause the uneven distribution of electrode ions, resulting in unstable output response, namely tremor behavior.
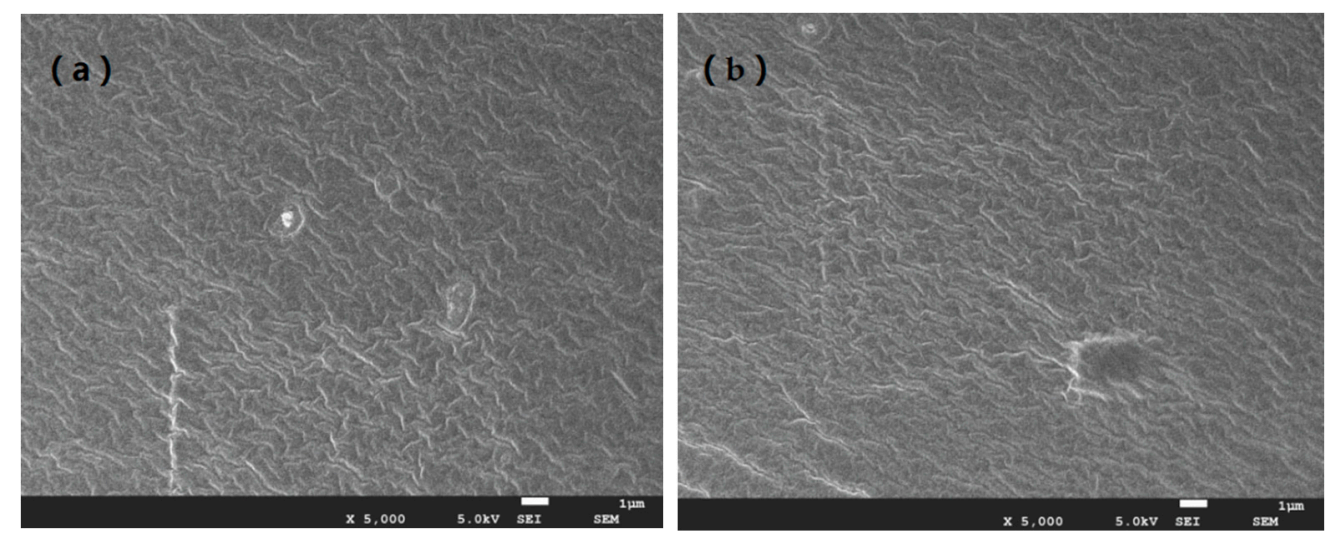

Figure 5. Surface microscopic structures: (a) Actuation film sample 1 (5000 times); (b) Actuation film sample 2 (5000 times). 
Based on the above bending mechanism, time dependent displacement data of sample 1 (40 $\mathrm{mm} \times$ $5 \mathrm{~mm} \times 0.5 \mathrm{~mm}$ ) was collected at $3 \mathrm{~V}$ voltage as shown in Figure 6 . It is easy to discover that the changes in displacement are fluctuating, but the general trend is monotonically rising within the time period. Regarding the displacement, if it decreases suddenly and then reverts to its last increasing state and the maximum peak-to-peak value or duration value of this wave is no less than a specific value, the tremor of artificial muscle is considered to happen. In particular, tremor behaviors are marked in circles. In addition, the thresholds of peak-to-peak value and duration are set as $0.2 \mathrm{~mm}$ and $1.5 \mathrm{~s}$, respectively.

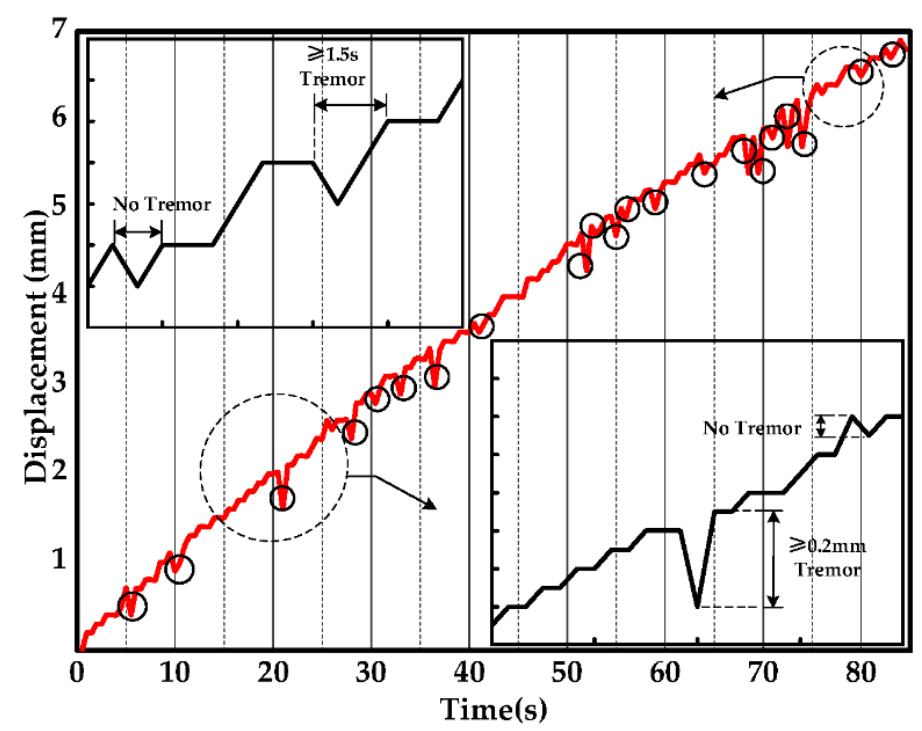

Figure 6. Displacement versus time curve at 3 V DC voltage. DC: direct current.

The displacement data in the first $65 \mathrm{~s}$ is selected as the original sequence and the last $20 \mathrm{~s}$ is used to test the accuracy of prediction. Table 1 shows the original and testing sequence of tremor occurrence times and the maximum peak-to-peak values with a time unit of $5 \mathrm{~s}$, respectively. Without loss of generality, if no tremor occurrs in a specific time unit, the peak-to-peak value is set as $0 \mathrm{~mm}$.

Table 1. Original sequence and test sequence of occurrence times and maximum peak-to-peak values.

\begin{tabular}{|c|c|c|c|c|c|c|c|}
\hline Time (s) & $\begin{array}{c}\text { Time Series } \\
\text { Value }\end{array}$ & $\begin{array}{l}\text { Occurrence } \\
\text { Times }\end{array}$ & $\begin{array}{l}\text { Peak-to-Peak } \\
\text { Values (mm) }\end{array}$ & Time (s) & $\begin{array}{c}\text { Time Series } \\
\text { Value }\end{array}$ & $\begin{array}{c}\text { Occurrence } \\
\text { Times }\end{array}$ & $\begin{array}{l}\text { Peak-to-Peak } \\
\text { Values (mm) }\end{array}$ \\
\hline $0 \sim 5$ & 1 & 0 & 0 & $45 \sim 50$ & 10 & 0 & 0 \\
\hline $5 \sim 10$ & 2 & 2 & 0.3 & $50 \sim 55$ & 11 & 3 & 0.6 \\
\hline $10 \sim 15$ & 3 & 0 & 0 & $55 \sim 60$ & 12 & 2 & 0.2 \\
\hline $15 \sim 20$ & 4 & 0 & 0 & $60 \sim 65$ & 13 & 1 & 0.1 \\
\hline $20 \sim 25$ & 5 & 1 & 0.5 & $65 \sim 70$ & 14 & 2 & 0.6 \\
\hline $25 \sim 30$ & 6 & 1 & 0.4 & $70 \sim 75$ & 15 & 3 & 0.5 \\
\hline $30 \sim 35$ & 7 & 2 & 0.3 & $75 \sim 80$ & 16 & 1 & 0.1 \\
\hline $35 \sim 40$ & 8 & 1 & 0.4 & $80 \sim 85$ & 17 & 2 & 0.2 \\
\hline $40 \sim 45$ & 9 & 1 & 0.1 & & & & \\
\hline
\end{tabular}

\subsection{Improved Grey Catastrophe Prediction}

\subsubsection{GM $(1,1)$ Model}

The general idea of grey prediction is to establish the first-order differential equation about generated time sequence named $\operatorname{GM}(1,1)$ model and forecast the occurrence time of forthcoming abnormal values based on the inherent regularity [32]. In particular, the time sequence is divided into equal time intervals. The threshold for determining abnormal values mainly depends on the actual situation and experiment methods when implementing the catastrophe prediction. 


\subsubsection{Conventional GCP Method}

By specifying a threshold, the time sequence data of tremor behavior from $0 \mathrm{~s}$ to $65 \mathrm{~s}$ is considered as the original time sequence $Q^{(0)}=(q(1), q(2), \cdots, q(n))$, where $Q^{(0)}$ is a nonnegative sequence and $n$ is the number of the outliers.

The first-order accumulative generation operation (1-AGO) is given by

$$
Q^{(1)}=\left(q(1)^{(1)}, q(2)^{(1)}, \cdots, q(n)^{(1)}\right)
$$

Then, the generated mean sequence $Z^{(1)}$ of $Q^{(1)}$ is defined as:

$$
Z^{(1)}=\left(z(2)^{(1)}, z(3)^{(1)}, \cdots, z(n)^{(1)}\right)
$$

where $z(k)^{(1)}=0.5 q(k)^{(1)}+0.5 q(k-1)^{(1)}(k=2,3, \cdots, n)$.

The least square estimate of GM $(1,1)$ model is defined as:

$$
q(k)+a z(k)^{(1)}=b
$$

where $a$ and $b$ represent the development coefficient and the grey action of the prediction model, respectively.

Finally, the estimated equation of the training sequence can be expressed as

$$
\hat{q}(k+1)^{(0)}=\left(1-e^{a}\right)\left[q(1)-\frac{b}{a}\right] e^{-a k}
$$

\subsubsection{DAGCP Method}

The whole process of dynamic additional prediction is completed as follows:

1. Establishment of different time subsequences

The GM $(1,1)$ model typically requires at least four points, so the maximum starting point should be set to the $(n-4)$ th observation to ensure that there are no less than four points in the shortest subsequence. The subsequence size of $n-4$ can be established at the moment. Abnormal values time sequence and time subsequences are expressed as:

$$
\begin{gathered}
Q^{(0)}=(q(1), q(2), \cdots, q(i), \cdots, q(n)) \\
Q^{(0)}(i)=([q(i+1)-q(i)],[q(i+2)-q(i)], \cdots,[q(n)-q(i)])
\end{gathered}
$$

where $n$ is the number of the outliers as well as the dimension of original sequence and $i$ is the ordinal number of calculation starting point. For example, $i=1$ represents that the distances between the first and subsequent other points are computed to obtain a new data subsequence under the dimension of $n-1$. Normally, Response equation of catastrophe time subsequences can be obtained:

$$
\hat{q}(k+1)^{(0)}=\left(1-e^{a}\right)\left[q(i+1)-q(i)-\frac{b}{a}\right] e^{-a k}
$$

\section{Selection of time subsequence}

The optimal time subsequence is selected based on the grey correlation degree and model precision. Essentially, grey correlation degree is applied to analyze the model's fitting degree by making a comparison between differential subsequences and original sequence in terms of the approximate 
level. As known, the fitting degree is improved with the increase of grey correlation value. The relevant equation about grey correlation degree is shown as follows:

$$
\gamma_{i}=\frac{1}{n} \sum_{k=1}^{n} \xi_{i}(k) \quad k=1,2, \cdots, n ; i=1,2, \cdots, m
$$

where $\xi_{i}(k)$ is grey correlation coefficient and it can be calculated by

$$
\xi_{i}(k)=\frac{\min _{i} \min _{k}\left|x_{0}(k)-x_{i}(k)\right|+\rho \max _{i} \max _{k}\left|x_{0}(k)-x_{i}(k)\right|}{\left|x_{0}(k)-x_{i}(k)\right|+\rho \max _{i} \max _{k}\left|x_{0}(k)-x_{i}(k)\right|}
$$

where $\rho$ is the distinguishing coefficient of the correlation axiom and the value is set as 0.5 based on previous experience. If the grey correlation degree is greater than 0.6 , the model is considered as a satisfaction. Accordingly, the appropriate subsequence is picked out according to the model precision and correlation degree.

\section{Achievement of additional forecast}

Conventional GCP adopts a fixed model to make a forecast for multiple times, which can continuously cause the degradation of prediction precision owing to the immobilization of inherent parameters. In view of the immediacy and contingency in tremor behavior, the newly generated predicted value is added into the original subsequence for future prediction purpose after rounding down decimal places. The decimal places are omitted so as to be consistent with the original nonnegative integer data sequence.

\section{Discussion}

\subsection{Examination of Prediction Accuracy}

To analyze the reliability of DAGCP, the accuracy of models has to be tested. The data tested comes from the China's hydropower production from 2000 to 2015, and prediction results are given by Wang et al. [25] by seasonal autoregressive integrated moving average (SARIMA) method and GM $(1,1)$ are provided for a direct comparison (see Figure 7). It can be seen that the present method is in close agreement with the actual values and SARIMA. Thus, compared with conventional methods, DAGCP shows a fine prediction precision and reliability. The reason for excellent prediction performance is that various dimensions of time subsequences constructed based on different starting points weakens the effects of the initial value, and the selected subsequence with continuously updated values captures time-varying performance of the system. Next, this method will be used for the forecast of tremor occurrence time.

\subsection{The Investigation of Tremor Times}

During the response process of artificial muscle, tremor occurrence times in each time unit are extracted, which characterizes the occurrence frequency of the tremor, and can be used as an important index for the evaluation of tremor behavior.

By referencing Table 1, the lower limiting outlier of occurrence times covered by tremor behavior was assigned as 1 . Thus, the corresponding tremor data sequence within the first $65 \mathrm{~s}$ was:

$$
Q^{(0)}=(2,5,6,7,8,9,11,12,13)
$$

When $i=1$, the distances between the first and subsequent other points were computed to obtain a new data subsequence:

$$
Q^{(0)}(1)=(3,4,5,6,7,9,10,11)
$$


And then $i=2$, the next subsequence was given:

$$
Q^{(0)}(2)=(1,2,3,4,6,7,8)
$$

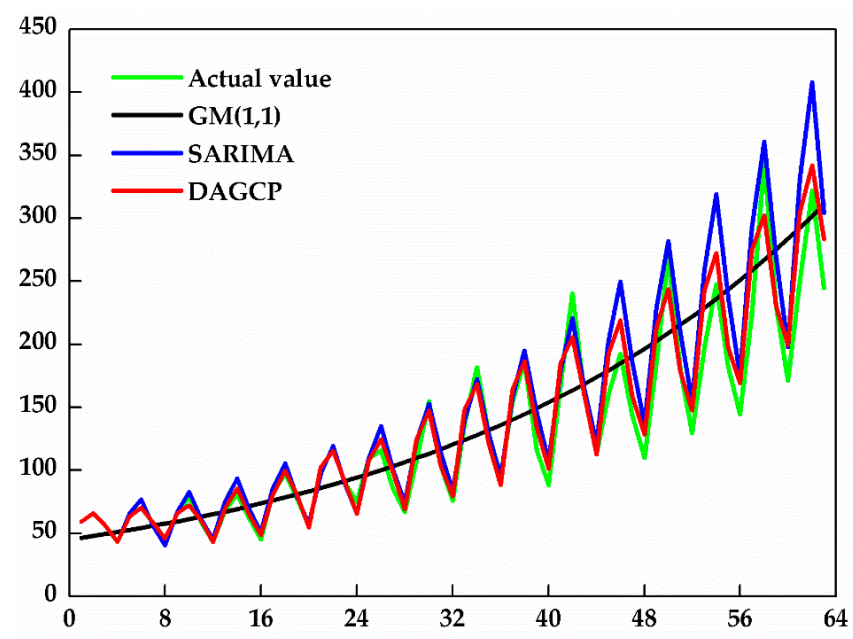

Figure 7. The distributions of values with DAGCP, SARIMA, GM $(1,1)$ and actual value. DAGCP: dynamic additional grey catastrophe prediction; SARIMA: seasonal autoregressive integrated moving average.

Analogously, based on the dimension of the original sequence, five new data subsequences were constructed under dimensions from 4 to 8 as the candidate models. The estimated values and original values of each subsequence with respect to ordinal $k$ were shown in Figure 8a-e, respectively. Meanwhile, model response, model accuracy, grey correction degree and fitting degree were calculated to evaluate the availability of the candidates (Table 2).

Analogously, based on the dimension of the original sequence, five new data subsequences were constructed under dimensions from 4 to 8 as the candidate models. The estimated values and original values of each subsequence with respect to ordinal $k$ were shown in Figure 8a-e, respectively. Meanwhile, model response, model accuracy, grey correction degree and fitting degree were calculated to evaluate the availability of the candidates (Table 2).

Table 2. Model test results of different subsequences about tremor occurrence times.

\begin{tabular}{ccccc}
\hline Sequence Dimension & $\begin{array}{c}\text { Model Response } \\
\hat{\boldsymbol{q}}(\boldsymbol{k}+\mathbf{1})^{(\mathbf{0})}\end{array}$ & Model Accuracy (\%) & $\begin{array}{c}\text { Grey Correlation } \\
\text { Degree }\end{array}$ & Fitting Degree \\
\hline 8 & $24.853 e^{0.16151 k}-21.853$ & 96.1503 & 0.6547 & satisfaction \\
7 & $9.2955 e^{0.24238 k}-8.2955$ & 89.6019 & 0.6009 & satisfaction \\
6 & $8.2308 e^{0.26852 k}-7.2308$ & 87.5976 & 0.5812 & dissatisfaction \\
5 & $7.9231 e^{0.2872 k}-6.9231$ & 86.4147 & 0.5774 & dissatisfaction \\
4 & $10.75 e^{0.2487 k}-9.75$ & 98.6546 & 0.5583 & dissatisfaction \\
\hline
\end{tabular}

From Table 2 and Figure 8, the results showed that the 4-D model had the highest prediction accuracy; however, it was not available for prediction because its grey correlation degree was less than 0.6 and the number of data samples was too small. Additionally, the lower correlation degree and accuracy of 5-D and 6-D models limited their applications in the prediction. Although both of them had high accuracy at the initial stage, compared with the 7-D subsequence, the model accuracy and grey correlation degree of 8-D were better as a whole, which showed a better fitting degree between the subsequence and original sequence. Therefore, the 8-D subsequence model about tremor occurrence times in unit time was used for prediction and the starting time point $q(1)$ was set as 2 . 

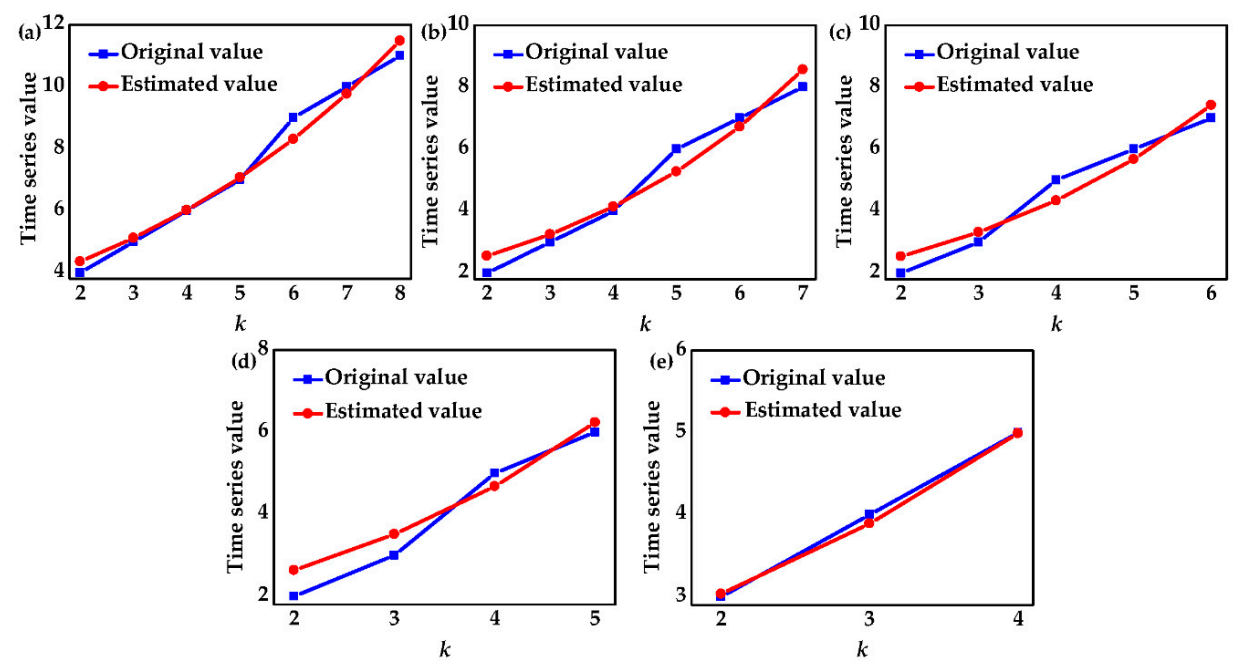

Figure 8. Estimated values and original values of each subsequence: (a) 8-D; (b) 7-D; (c) 6-D; (d) 5-D; (e) 4-D.

The estimated values and relative errors of conventional GCP and DAGCP were shown in Table 3. Specifically, the conventional GCP was constructed by the original time sequence. It is obvious that the actual number of tremors only occurred once during 75 80 s and was affected by process parameters, experimental conditions and human factors, as well as existing contingency. Hence, it was not necessary to predict ahead in this circumstance.

Table 3. Estimated values and relative errors of grey catastrophe prediction (GCP) and dynamic additional grey catastrophe prediction (DAGCP).

\begin{tabular}{ccccccc}
\hline & \multicolumn{2}{c}{ GCP } & \multicolumn{2}{c}{ DAGCP } \\
\hline \multirow{2}{*}{ Tremor Times } & $\begin{array}{c}\text { Time Series } \\
\text { Value } \boldsymbol{q}(\boldsymbol{k})^{(\mathbf{0})}\end{array}$ & $\begin{array}{c}\text { Actual Time } \\
\text { Domain (s) }\end{array}$ & $\begin{array}{c}\text { Estimated } \\
\text { Value } \hat{\boldsymbol{q}}(\boldsymbol{k})^{(\mathbf{0})}\end{array}$ & $\begin{array}{c}\text { Relative } \\
\text { Error (\%) }\end{array}$ & $\begin{array}{c}\text { Estimated } \\
\text { Value } \hat{\boldsymbol{q}}(\boldsymbol{k})^{(\mathbf{0})}\end{array}$ & $\begin{array}{c}\text { Relative } \\
\text { Error (\%) }\end{array}$ \\
\hline 2 & 14 & $65 \sim 70$ & 15.39 & 9.93 & 15.49 & 3.50 \\
3 & 15 & $70 \sim 75$ & 17.51 & 16.73 & 17.05 & 13.67 \\
2 & 17 & $80 \sim 85$ & 19.91 & 17.12 & 18.93 & 11.35 \\
\hline
\end{tabular}

Note: Relative error $=\left|\frac{q(k)^{(0)}-\hat{q}(k)^{(0)}}{q(k)^{(0)}}\right| \times 100 \%$.

It was obvious that the occurrence times in $65 \sim 70 \mathrm{~s}, 70 \sim 75 \mathrm{~s}$ and $80 \sim 85 \mathrm{~s}$ were 2, 3 and 2, respectively. As shown in Table 3, there was a little difference between GCP and DAGCP in the relative error during 65 70 s. However, the relative error of DAGCP was smaller than GCP after 70 s. Therefore, the prediction accuracy of DAGCP was superior to that of GCP as a whole.

\subsection{The Investigation of Peak-to-Peak Values}

The maximum peak-to-peak values (the difference between adjacent crests and troughs) in unit time are extracted, which characterizes the severe degree of tremor, and also can be used for the evaluation of tremor behavior. Here, the lower limiting outlier was assigned as $0.2 \mathrm{~mm}$. In addition, the corresponding data sequence within 65 s was:

$$
Q^{(0)}=(2,5,6,7,8,11,12)
$$

When $i=1$, a new data subsequence was: $Q^{(0)}(1)=(3,4,5,6,9,10)$.

Thus, three new data subsequences were constructed under the dimensions from 4 to 6 . The estimated values and original values were shown in Figure $9 \mathrm{a}-\mathrm{c}$, respectively. In addition, 
the model response, model accuracy, grey correction degree and fitting degree were displayed in Table 4.

Table 4. Model test results of different subsequences about tremor peak-to-peak values.

\begin{tabular}{ccccc}
\hline $\begin{array}{c}\text { Sequence } \\
\text { Dimension }\end{array}$ & $\begin{array}{c}\text { Model Response } \\
\hat{\boldsymbol{q}}(\boldsymbol{k}+\mathbf{1})^{(\mathbf{0})}\end{array}$ & Model Accuracy (\%) & $\begin{array}{c}\text { Grey Correlation } \\
\text { Degree }\end{array}$ & Fitting Degree \\
\hline 6 & $14.906 e^{0.23688 k}-11.906$ & 95.8616 & 0.6252 & satisfaction \\
5 & $4.9444 e^{0.3848 k}-3.9444$ & 87.1655 & 0.6117 & satisfaction \\
4 & $5.125 e^{0.42105 k}-4.125$ & 81.2634 & 0.6081 & satisfaction \\
\hline
\end{tabular}

From Table 4 and Figure 9, although the grey correlation degree had achieved the basic requirement, the prediction precision of 4-D and 5-D models limited their applications in the prediction. Among them, 6-D model had the highest model accuracy and grey correlation degree, which showed a more accurate fitting degree. Thus, the 6-D model about tremor peak-to-peak value in unit time was used for the prediction and $q(1)$ was also set as 2 .

The estimated values and relative errors were shown in Table 5. The actual peak-to-peak value was less than $0.2 \mathrm{~mm}$ during $75 \sim 80 \mathrm{~s}$, which was allowed to happen. Therefore, it was not necessary to predict ahead in this circumstance.
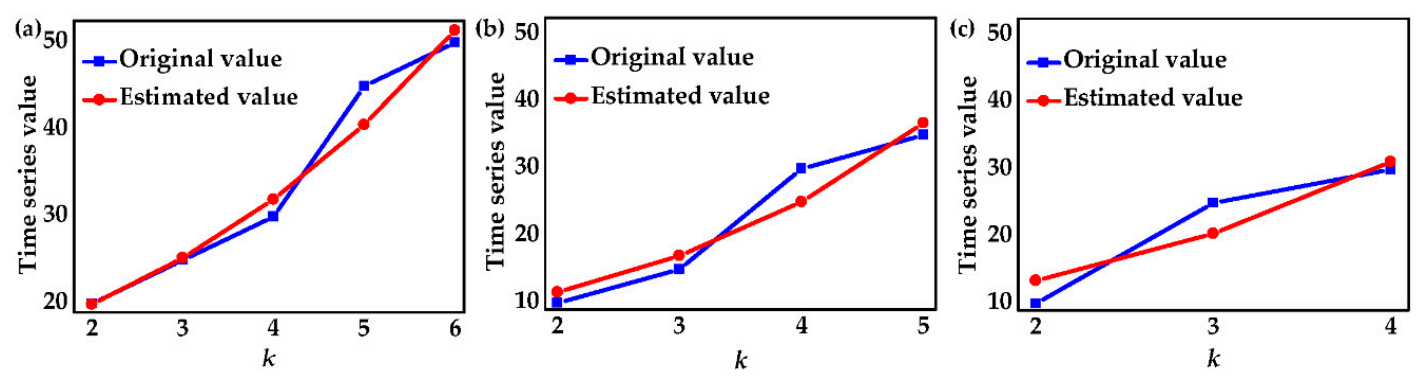

Figure 9. Estimated values and original values of each subsequence. (a) 6-D; (b) 5-D; (c) 4-D.

Table 5. Estimated values and relative errors of GCP and DAGCP.

\begin{tabular}{ccccccc}
\hline & & \multicolumn{2}{c}{ GCP } & \multicolumn{2}{c}{ DAGCP } \\
\hline $\begin{array}{ccccc}\text { Peak-to-Peak } \\
\text { Values }(\mathbf{m m})\end{array}$ & $\begin{array}{c}\text { Time Series } \\
\text { Value } \boldsymbol{q}(\boldsymbol{k})^{(\mathbf{0})}\end{array}$ & $\begin{array}{c}\text { Actual Time } \\
\text { Domain }(\mathbf{s})\end{array}$ & $\begin{array}{c}\text { Estimated } \\
\text { Value } \hat{\boldsymbol{q}}(\boldsymbol{k})^{(\mathbf{0})}\end{array}$ & $\begin{array}{c}\text { Relative } \\
\text { Error (\%) }\end{array}$ & $\begin{array}{c}\text { Estimated } \\
\text { Value } \hat{\boldsymbol{q}}(\boldsymbol{k})^{(\mathbf{0})}\end{array}$ & $\begin{array}{c}\text { Relative } \\
\text { Error (\%) }\end{array}$ \\
\hline 0.6 & 14 & $65 \sim 70$ & 14.64 & 4.57 & 13.52 & 3.43 \\
0.5 & 15 & $70 \sim 75$ & 17.46 & 16.40 & 16.35 & 9.00 \\
0.2 & 17 & $80 \sim 85$ & 20.80 & 22.35 & 20.18 & 18.71 \\
\hline
\end{tabular}

In the above analysis, the peak-to-peak values in $65 \sim 70 \mathrm{~s}, 70 \sim 75 \mathrm{~s}$ and $80 \sim 85 \mathrm{~s}$ were $0.6 \mathrm{~mm}$, $0.5 \mathrm{~mm}$ and $0.2 \mathrm{~mm}$, respectively. As shown in Table 5, the relative error of DAGCP was obviously less than that of GCP.

To validate the effectiveness and accuracy of the proposed method, the catastrophe prediction results of 10 groups of chitosan-based artificial muscles with different process parameters based on GCP and DAGCP were shown in Table 6 . Here, the data in the first $70 \mathrm{~s}$ was selected as original sequence and the last $10 \mathrm{~s}$ was used to assess the prediction accuracy. The lower thresholds of occurrence times and peak-to-peak values were assigned as 2 and $0.2 \mathrm{~mm}$, respectively. If either of the conditions was satisfied, the tremor is considered to happen. 
Table 6. Estimated values and relative errors of GCP and DAGCP.

\begin{tabular}{|c|c|c|c|c|c|c|c|c|c|}
\hline \multirow[b]{2}{*}{$\begin{array}{l}\text { Group } \\
\text { Order }\end{array}$} & \multirow[b]{2}{*}{$\begin{array}{l}\text { Tremor } \\
\text { Times }\end{array}$} & \multirow[b]{2}{*}{$\begin{array}{l}\text { Peak-to-Peak } \\
\text { Values (mm) }\end{array}$} & \multirow[b]{2}{*}{$\begin{array}{c}\text { Time Series } \\
\text { Value }\end{array}$} & \multicolumn{3}{|c|}{ GCP } & \multicolumn{3}{|c|}{ DAGCP } \\
\hline & & & & D & $\begin{array}{c}\text { Estimated } \\
\text { Value } \hat{\boldsymbol{q}}(\boldsymbol{k})^{(0)}\end{array}$ & $\begin{array}{l}\text { Relative } \\
\text { Error (\%) }\end{array}$ & D & $\begin{array}{c}\text { Estimated } \\
\text { Value } \hat{\boldsymbol{q}}(\boldsymbol{k})^{(0)}\end{array}$ & $\begin{array}{l}\text { Relative } \\
\text { Error (\%) }\end{array}$ \\
\hline \multirow[b]{2}{*}{1} & 1 & 0.2 & 15 & \multirow[b]{2}{*}{10} & 17.47 & 16.47 & 8 & 15.55 & 3.67 \\
\hline & 2 & 0.4 & 16 & & 20.69 & 29.31 & 9 & 18.03 & 13.53 \\
\hline 2 & 2 & 0.3 & 15 & 10 & 17.98 & 19.87 & 8 & 16.48 & 9.87 \\
\hline \multirow[b]{2}{*}{3} & 1 & 0.4 & 15 & \multirow{2}{*}{12} & 17.14 & 14.27 & 10 & 16.42 & 9.47 \\
\hline & 3 & 0.7 & 16 & & 19.74 & 23.38 & 11 & 18.69 & 16.81 \\
\hline \multirow[b]{2}{*}{4} & 2 & 0.3 & 15 & \multirow{2}{*}{12} & 17.05 & 13.67 & 10 & 17.26 & 15.07 \\
\hline & 1 & 0.3 & 16 & & 19.46 & 21.63 & 11 & 19.02 & 18.88 \\
\hline \multirow{2}{*}{5} & 2 & 0.2 & 15 & \multirow{2}{*}{11} & 17.85 & 19.00 & 10 & 16.78 & 11.87 \\
\hline & 1 & 0.4 & 16 & & 20.79 & 29.94 & 11 & 18.38 & 14.88 \\
\hline 6 & 2 & 0.2 & 16 & 11 & 18.41 & 15.06 & 10 & 16.89 & 5.56 \\
\hline \multirow[b]{2}{*}{7} & 2 & 0.6 & 15 & \multirow{2}{*}{13} & 17.84 & 18.93 & 6 & 16.29 & 8.60 \\
\hline & 2 & 0.4 & 16 & & 20.47 & 27.94 & 7 & 18.44 & 15.25 \\
\hline \multirow{2}{*}{8} & 3 & 0.5 & 15 & \multirow{2}{*}{12} & 17.23 & 14.87 & 10 & 16.12 & 7.47 \\
\hline & 1 & 0.4 & 16 & & 19.45 & 21.56 & 11 & 18.03 & 12.69 \\
\hline \multirow{2}{*}{9} & 3 & 0.3 & 15 & \multirow{2}{*}{10} & 17.87 & 19.13 & 6 & 16.33 & 8.87 \\
\hline & 3 & 0.3 & 16 & & 21.18 & 32.38 & 7 & 18.83 & 17.69 \\
\hline 10 & 2 & 0.2 & 15 & 12 & 16.77 & 11.80 & 8 & 15.43 & 2.87 \\
\hline
\end{tabular}

From the comparative analysis, the proposed DAGCP can better identify the occurrence tendency of tremor behavior and individual variation of original data, and achieve smaller relative errors. Therefore, this novel method is viable and reliable for predicting the tremor behavior of artificial muscle.

\section{Conclusions}

In this paper, we illustrate the tremor mechanism of artificial muscle and forecast the tremor occurrence time using GCP based methods. In order to further improve the prediction accuracy, we propose a new method called DAGCP by integrating sequence optimization mechanism and dynamic additional strategy into the conventional GCP. Its excellent prediction performance indicates that various dimension of time subsequences constructed based on different starting points weakens the effects of the initial value, and the selected subsequence with continuously updated values captures time-varying performance of the system.

As shown in the case study of artificial muscle, the novel DAGCP can earlier and more accurately forecast the forthcoming tremor time than conventional GCP. Therefore, it can be selected to provide the preparation time for parameter adjustment of artificial muscles' online behaviors and realize the suppression of tremor behavior. In summary, this method has the following advantages: the degradation of prediction accuracy caused by the immobilization of original parameters is prevented; dynamic input, real-time update and gradual forecast of the model can be realized and widely used in the industry, agriculture and medicine, etc.

Acknowledgments: This research is financially supported by the National Natural Science Foundation of China (NSFC) (Grant No. 51675112), the Fundamental Research Funds for the Central Universities (HEUCFP201733) and the Faculty Research Grants of Macau University of Science and Technology (FRG-17-025-MSB).

Author Contributions: Yu Fu, Jianjun Yao, Honghao Zhao and Gang Zhao initiated the idea; Yu Fu performed all experiments and took the photographs in this article; $\mathrm{Yu} \mathrm{Fu}$ and Zhenshuai Wan wrote the main manuscript; $\mathrm{Yu} \mathrm{Fu}$, and Gang Zhao collected and analyzed the results; all authors participated in refining the submitted manuscript.

Conflicts of Interest: The authors declare no conflict of interest. 


\section{References}

1. Ma, M.M.; Guo, L.; Anderson, D.G.; Langer, R. Bio-Inspired Polymer Composite Actuator and Generator Driven by Water Gradients. Science 2013, 339, 186-189. [CrossRef] [PubMed]

2. Ahmad, M.; Xu, B.; Purnawali, H.; Fu, Y.P.; Huang, W.M.; Miraftab, M.; Luo, J.K. High Performance Shape Memory Polyurethane Synthesized with High Molecular Weight Polyol as the Soft Segment. Appl. Sci. 2012, 2, 535-548. [CrossRef]

3. Kong, L.R.; Chen, W. Carbon Nanotube and Graphene-based Bioinspired Electrochemical Actuators. Adv. Mater. 2014, 26, 1025-1043. [CrossRef] [PubMed]

4. Tung, S.; Witherspoon, S.R.; Roe, L.A.; Silano, A.; Maynard, D.P.; Ferraro, N. A MEMS-based flexible sensor and actuator system for space inflatable structures. Smart Mater. Struct. 2001, 10, 1230-1239. [CrossRef]

5. Brunetto, P.; Fortuna, L.; Giannone, P.; Graziani, S.; Strazzeri, S. Static and Dynamic Characterization of the Temperature and Humidity Influence on IPMC Actuators. IEEE Trans. Instrum. Meas. 2010, 59, 893-908. [CrossRef]

6. Shahinpoor, M.; Kim, K.J. Ionic polymer-metal composites: III. Modeling and simulation as biomimetic sensors, actuators, transducers, and artificial muscles. Smart Mater. Struct. 2004, 13, 1362-1388. [CrossRef]

7. Bar-Cohen, Y.; Zhang, Q.M. Electroactive polymer actuators and sensors. MRS Bull. 2008, 33, $173-181$. [CrossRef]

8. Kim, J.; Wang, N.G.; Chen, Y.; Lee, S.K.; Yun, G.Y. Electroactive-paper actuator made with cellulose/NaOH/ urea and sodium alginate. Cellulose 2007, 14, 217-223. [CrossRef]

9. Baughman, R.H. Materials science-Muscles made from metal. Science 2003, 300, 268-269. [CrossRef] [PubMed]

10. Aoyagi, W.; Omiya, M. Anion Effects on the Ion Exchange Process and the Deformation Property of Ionic Polymer Metal Composite Actuators. Materials 2016, 9, 479. [CrossRef] [PubMed]

11. Li, J.Z.; Ma, W.J.; Song, L.; Niu, Z.G.; Cai, L.; Zeng, Q.S.; Zhang, X.X.; Dong, H.B.; Zhao, D.; Zhou, W.Y.; et al. Superfast-Response and Ultrahigh-Power-Density Electromechanical Actuators Based on Hierarchal Carbon Nanotube Electrodes and Chitosan. Nano Lett. 2011, 11, 4636-4641. [CrossRef] [PubMed]

12. Lu, L.H.; Chen, W. Biocompatible Composite Actuator: A Supramolecular Structure Consisting of the Biopolymer Chitosan, Carbon Nanotubes, and an Ionic Liquid. Adv. Mater. 2010, 22, 3745-3748. [CrossRef] [PubMed]

13. Jager, E.W.; Smela, E.; Inganas, O. Microfabricating conjugated polymer actuators. Science 2000, 290, 1540-1545. [CrossRef] [PubMed]

14. Escudero, A.Z.; Alvarez, J.; Leija, L. Development and characterisation of electromechanical muscles for driving trans-humeral myoelectric prostheses. Prosthet. Orthot. Int. 2002, 26, 226-234. [CrossRef] [PubMed]

15. Kim, T.H.; Kwon, C.H.; Lee, C.; An, J.; Phuong, T.T.T.; Park, S.H.; Lima, M.D.; Baughman, R.H.; Kang, T.M.; Kim, S.J. Bio-inspired Hybrid Carbon Nanotube Muscles. Sci. Rep. 2016, 6, 26687. [CrossRef] [PubMed]

16. Deng, J.-L. Control problems of grey systems. Syst. Control Lett. 1982, 5, 288-294.

17. Chiang, J.Y.; Chen, C.K. Application of grey prediction to inverse nonlinear heat conduction problem. Int. J. Heat Mass Transf. 2008, 51, 576-585. [CrossRef]

18. Zhang, X.N.; Zhang, L.; Zhang, Y.H.; Liao, Z.Y.; Song, J.L. Predicting trend of early childhood caries in mainland China: A combined meta-analytic and mathematical modelling approach based on epidemiological surveys. Sci. Rep. 2017, 7, 6507. [CrossRef] [PubMed]

19. Guo, X.J.; Liu, S.F.; Yang, Y.J.; Jin, J.L. Forecasting China's $\mathrm{SO}_{2}$ Emissions by the Nonlinear Grey Bernoulli Self-memory Model. J. Grey Syst. 2016, 28, 77-87.

20. Zhang, Y.J.; Wang, C.G.; Yan, L.; Li, D.L.; Zhang, X.S. An On-Line Oxygen Forecasting System for Waterless Live Transportation of Flatfish Based on Feature Clustering. Appl. Sci. 2017, 7, 957. [CrossRef]

21. Zhao, H.R.; Guo, S. Using GM (1,1) Optimized by MFO with Rolling Mechanism to Forecast the Electricity Consumption of Inner Mongolia. Appl. Sci. 2016, 6, 20. [CrossRef]

22. Wu, H.; Zeng, B.; Zhou, M. Forecasting the Water Demand in Chongqing, China Using a Grey Prediction Model and Recommendations for the Sustainable Development of Urban Water Consumption. Int. J. Environ. Res. Public Health 2017, 14, 1386. [CrossRef] [PubMed]

23. Meng, F.D.; Liu, Y.; Liu, L.; Li, Y.; Wang, F.H. Studies on Mathematical Models of Wet Adhesion and Lifetime Prediction of Organic Coating/Steel by Grey System Theory. Materials 2017, 10, 715. [CrossRef] [PubMed] 
24. Liu, S.F.; Forrest, J.; Yang, Y.J. Advances in Grey Systems Research. J. Grey Syst. 2013, 25, 1-18.

25. Wang, Z.X.; Li, Q.; Pei, L.L. Grey forecasting method of quarterly hydropower production in China based on a data grouping approach. Appl. Math. Model 2017, 51, 302-316. [CrossRef]

26. Huang, Y.F.; Wang, C.N.; Dang, H.S.; Lai, S.T. Evaluating Performance of the DGM(2,1) Model and Its Modified Models. Appl. Sci. 2016, 6, 73. [CrossRef]

27. Zhang, L.P.; Wang, L.; Zheng, Y.L.; Wang, K.; Zhang, X.L.; Zheng, Y.J. Time Prediction Models for Echinococcosis Based on Gray System Theory and Epidemic Dynamics. Int. J. Environ. Res. Public Health 2017, 14, 262. [CrossRef] [PubMed]

28. Shen, X.J.; Ou, L.M.; Chen, X.J.; Zhang, X.; Tan, X.R. The Application of the Grey Disaster Model to Forecast Epidemic Peaks of Typhoid and Paratyphoid Fever in China. PLoS ONE 2013, 8, e60601.

29. Yuan, C.Y.; Li, J.X.; Zhang, R.; Liu, J.Y. Grey and Fuzzy Evaluation of Information System Disaster Recovery Capability. Proc. Int. Conf. Adv. Comput. Sci. Eng. 2013, 42, 298-302.

30. Yin, K.D.; Zhang, Y.; Li, X.M. Research on Storm-Tide Disaster Losses in China Using a New Grey Relational Analysis Model with the Dispersion of Panel Data. Int. J. Environ. Res. Public Health 2017, 14, 1330. [CrossRef] [PubMed]

31. Aoues, S.; Di Loreto, M.; Eberard, D.; Marquis-Favre, W. Hamiltonian systems discrete-time approximation: Losslessness, passivity and composability. Syst. Control Lett. 2017, 110, 9-14. [CrossRef]

32. Yuan, C.Q.; Liu, S.F.; Fang, Z.G. Comparison of China's primary energy consumption forecasting by using ARIMA (the autoregressive integrated moving average) model and $\operatorname{GM}(1,1)$ model. Energy 2016, 100, 384-390. [CrossRef]

(c) 2018 by the authors. Licensee MDPI, Basel, Switzerland. This article is an open access article distributed under the terms and conditions of the Creative Commons Attribution (CC BY) license (http://creativecommons.org/licenses/by/4.0/). 